\title{
The Quadrapolar Character of the Markovnikov Reaction Transition State
}

\author{
Stefan Franzen ${ }^{1}$, Kristin H. Cochran, ${ }^{1}$ James Weng, ${ }^{1}$ \\ Libero Bartolotti ${ }^{2}$ and Bernard Delley ${ }^{3}$ \\ ${ }^{1}$ Department of Chemistry, North Carolina State University, Raleigh, North Carolina 27695, \\ $U S A$ \\ ${ }^{2}$ Department of Chemistry, East Carolina University, Greenville, North Carolina 27858, USA \\ ${ }^{3}$ Paul-Scherer Institute, CH-5232, Villigen, Switzerland
}

\section{Submitted to:}

Chemical Physics

Submitted: July 27, 2015

Running Title: Quadrapolar Character of the Markovnikov Transition State

\section{*Author for Correspondence}

Stefan Franzen, Ph.D

Department of Chemistry

North Carolina State University

Raleigh, North Carolina 27695

Phone: 919-515-8915

Fax: 919-515-8920

Email: franzen@ncsu.edu 


\begin{abstract}
The properties of the transition states for the electrophilic addition reactions of four molecules of the type $\mathrm{HX}(\mathrm{X}=\mathrm{Br}, \mathrm{Cl}, \mathrm{F}$ and $\mathrm{OH})$ to 1-propene form 2-X propane by the Markovnikov mechanism have been calculated using Density Functional Theory (DFT). A comparative study of the transition state along the reaction path for both M and AM addition was studied in order to understand the origins of regioselectivity of $\mathrm{H}_{2} \mathrm{O}$. The quadrapolar nature of the transition state is arises because of a sequential mechanism, in which the addition across the $\pi$-bond occurs in two steps, first $\mathrm{H}^{+}$and then $\mathrm{X}^{-}$. The $\mathrm{M}$ reaction mechanism is consistent with a $\mathrm{H}^{+} \mathrm{X}^{-}$dipole which induces an oppositely polarized $\mathrm{C}^{-} \mathrm{C}^{+}$dipole in the transition state, resulting in a quadrupole. The $\mathrm{C}^{-} \mathrm{C}^{+}$dipole in the $\mathrm{M}$ mechanism is consistently larger than the $\mathrm{C}^{+} \mathrm{C}^{-}$dipole of the AM transition state for all species studied.
\end{abstract}

\title{
Keywords
}

Nudged elastic band; intrinsic reaction coordinate; transition state; Fukui function; softness; regioselectivity 


\section{Introduction}

The reactivity of $\mathrm{H}_{2} \mathrm{O}$ with $\pi$-bonds has important applications in industry and biology. Industrial production of 2-propanol by hydration of 1-propene was one of the first processes developed in chemical industry. This hydration reaction is has been optimized by experimentation over the years. Acid catalysis is known to play an important role and appropriate catalysts can alter the regioselectivity. However, the fundamental relationship between the hydration of alkenes and Markovnikov addition in organic synthesis has not been fully elucidated despite their obvious similarities. Moreover, ground state hydration processes, which can occur for any isolated $\pi$-bond have a relationship to a number of important photohydration reactions. [1] While the electrophilic addition of $\mathrm{H}_{2} \mathrm{O}$ across a $\pi$-bond is a relatively simple reaction, there is some uncertainty in the interpretation of the experimental data given the nature of the pyrimidine excited state. For this reason, we have sought a test case that is a well understood chemical reaction with clear trends that can be used to further test and validate the approaches used previously. This study focuses on the Markovnikov addition to propene as such a test case. While the reactivity under Markovnikov conditions is clear for strong acids such as $\mathrm{HCl}$ and $\mathrm{HBr}$, it is more challenging to explain the reactivity of weak acids, which is needed in order to understand the addition of $\mathrm{H}_{2} \mathrm{O}$.

A Markovnikov addition is a regioselective reaction, which results in halogenation of the carbon atom with the greatest number of alkyl bonds. By comparing a series of molecules, $\mathrm{HX}=$ $\mathrm{HBr}, \mathrm{HCl}, \mathrm{HF}$ and $\mathrm{H}_{2} \mathrm{O}$, we can make a connection with previous work and relate the results to a large body of experimental and theoretical work. [2-7] A recent study has shown a correlation between the rates of electrophilic addition and the hydrogenation energy of a large number of systems.[8] This correlation apparently breaks down for $\mathrm{H}_{2} \mathrm{O}$ and for highly polar media or under acid-catalysis. Anti-Markovnikov addition can be achieved by appropriate catalysts. Indeed, catalytic anti-Markovnikov hydration has been one of the important chemical challenges for the past 20 years.[9] These examples show the active interest in synthesis and the need to understand the role of polarization in electrophilic additions. This recent background further supports our choice of electrophiles in the present study of the mechanism of Markovnikov additions.

Density functional theory (DFT) methods have been used to correlate reactivity with molecular properties including energy, charge, and polarizability.[10-12] Correlations can be 
made with the electron density as the central quantity for characterization of molecular properties. [6] These ideas have been further developed in the concept of a "molecular face" presented by a molecule, which is considered a more accurate predictor of reactivity.[7] These concepts have been applied to the regioselectivity of the addition of HX-type molecules across the $\pi$-bond. [2] In this study our focus is on the effects of both the acidity and the polarity of the electrophile. This differentiates the present study from previous comparisons of the reactivity of different olefins. [10-12]

The alternative statement of Markovnikov's rule is an acid HX protonates the carbon with the fewest alkyl substituents when it adds to dicarbon $\pi$-bond. This is the corollary to the statement that the conjugate base, $\mathrm{X}^{-}$, forms a bond to the carbon atom with the greatest number of substituents. The basis for this rule is the fact that the carbon with the most alkyl substituents forms a more stable carbocation following protonation of the $\pi$-bond. The hypothesis implies that electrophilic protonation precedes nucleophilic attack, i.e. the process is sequential rather than concerted. Propene is perhaps the simplest case for computational testing of the role of acidity in Markovnikov's rule. In the example of propene, protonation of the terminal carbon creates a secondary carbocation, which is more stable than the primary carbocation formed by the protonation of the secondary carbon. Thus, $\mathrm{HCl}$ and $\mathrm{HBr}$, which are strong acids, tend to form adducts with the secondary carbocation in the transition state leading to the Markovnikov products (see Figure S1). [13]

By comparing the transition states of both the Markovnikov and anti-Markovnikov addition reactions, it is possible to calculate a rate constants from first principles. This can be done for a series of molecules $\mathrm{HX}$, where $\mathrm{X}=\mathrm{Br}, \mathrm{Cl}, \mathrm{F}$ and $\mathrm{OH}$. Based on the observed regioselectivity and inferred carbocation stability, one would predict a lower energy transition state for the Markovnikov than for the anti-Markovnikov route. Hence, the activation energy should be lower and rate constant should be greater for the Markovnikov pathway. In the examples studied here the thermodynamic product is also the Markovnikov product, which provides a further test for the computational approach. The comparison of the two products leads us to ask, when does the Markovnikov rule break down? The introduction of peroxides or other reagents that create radicals changes the preferred pathway to the anti-Markovnikov pathway. [14] The radical pathway is allowed for halogens and thus addition to the terminal carbon is the 
preferred route in this case. [4] Given the conventional view of Markovnikov addition by a strong acid, the question remains whether a weak acid will violate the rule. Specifically, Markovnikov's rule is ideally true for strong acids such as $\mathrm{HCl}$, but then by that reasoning why should the rule be obeyed by a weak acid such as $\mathrm{H}_{2} \mathrm{O}$ ? Our comparison will test predicted regioselectivity for a series of acids by examining the reactivity of weak acids, $\mathrm{HF}$ and $\mathrm{H}_{2} \mathrm{O}$, as well as the strong acid, $\mathrm{HCl}$. $\mathrm{HBr}$ is also a strong acid, but it has a significant propensity to add via a radical mechanism, which is why it is less studied in computational work. [14] In order to fully understand the implications of the transition state calculation, a statistical mechanical calculation of the transition rate constant will be implemented based on the ratio of the partition functions for the transition and reactant states. As shown in the results, this aspect of the calculation turns out to be crucial for an accurate interpretation of the computational results. [15]

The reaction path must be determined based on a calculation of the equilibrium structures of the reactants and products. The equilibrium structure of the reactant complex of HX and $\mathrm{CH}_{3} \mathrm{CH}=\mathrm{CH}_{2}$ is nearly perpendicular to the $\pi$-bond with the $\mathrm{H}$ atom of $\mathrm{HX}$ directed towards the mid-point of the $\pi$-bond. Calculation of the transition state energy is possible using the nudged elastic band (NEB) method, which consists of a series of structures linearly connecting the reactant product structures. [16] The NEB method has been combined several other computational approaches to refine and validate the transition state. [16-21] When bonds are broken it is possible that the ratio of partition functions for the transition and reactant states will provide a significant contribution to the transition probability, and therefore to the calculated activation energy. The vibrational partition function turns out to be important in the present case, which is perhaps understandable simply based on the fact that there are only a few high frequency vibrations affected by the M and AM addition reaction. Use of density functional theory (DFT) methods to calculate reaction paths is highly desirable due to the relatively low cost of the method, particularly when compared to post-Hartree-Fock (HF) approaches. [22] The present study presents a validation of the approach and a demonstration of the utility of the method since the density can be interpreted in terms of the Fukui function, which can be combined the molecular softness function to provide a detailed view of the origins of regioselectivity. 


\section{Methods}

Density Functional Theory DFT calculations were carried out using $\mathrm{DMol}^{3}$ (3.9 version PSI 20120307-m10m). [23, 24] Molecules were built using Spartan Student Edition V. 4 version 4.1.2. Molecules were viewed using VMD 1.9.1. The DMol ${ }^{3}$ DFT [25] code was used for numerical evaluation of energy and electron density of a series of molecules undergoing Markovnikov additions. The anti-Markovnikov addition was also calculated for comparison. The PBE functional was used for all calculations implemented using the DNP numerical basis set. $[26,27]$ This basis set is equivalent to a double-zeta plus polarization basis set in Gaussian or other codes. A cut-off of 20 Bohrs was used together with a fine grid for the numerical calculation. Structures were geometrically optimized using $\mathrm{DMol}^{3}$ until the change in the energy was less than the convergence criterion of $10^{-6}$ Hartrees (Ha) on two subsequent steps of the minimization algorithm. Recent advances using a nudged elastic band (NEB) and ancillary methods have proven useful for locating transition states. [16, 21, 28] The present study contributes to a body of research demonstrating the validity of DFT methods for accurate prediction of transition states. We describe the calculation and validation of the transition trajectory using the NEB method to obtain the initial structures that bracket the transition state. A systematic search based on the program DIMER uses two structures that are on either side of the transition state to locate the actual saddle point. [17, 20] Product and reactant molecules (propene, HX, 2-halogenopropane (HXMP), and 1-halogenopropane (HXAMP), where X = F, Cl, $\mathrm{Br}$ and $\mathrm{OH}$, were built in Spartan. A frequency calculation was performed on each individual compound using $\mathrm{DMol}^{3}$. [23, 24] A reaction path was generated for both the Markovnikov and the anti-Markovnikov reaction pathways using the Reaction Preview Tool in Materials Studio (version 4.4 from Accelrys). The preview tool creates a series of 30 structures which linearly connect the reactant to the product. The NEB calculation was carried out using code adapted from Henkelman et al. [18, 21, 29] by Bartolotti. Once convergence was reached based on the nudged elastic band (defined as a difference $<10^{-4}$ Hartrees/ $\AA$ in the gradient and $<10^{-6}$ Hartrees in the energy per step), the structures were submitted to the program DIMER written by Henkelman et al. and adapted for use with $\mathrm{DMol}^{3}$ by Bartolotti. [17, 29, 30] DIMER runs DMol ${ }^{3}$ in a script to systematically search for the transition state given two geometries that bracket the transition state. The result obtained from DIMER was further tested using the TS_SEARCH keyword in $\mathrm{DMol}^{3}$. This option uses the transition state search method developed by Schlegel to 
further refine the structure. [31] Typically, the change in structure is extremely small in the final optimization steps. The reaction trajectory energies and vibrational mode energies expanded about the saddle point were read into Igor6.0 (Wavemetrics, Inc.) and plotted for pathway and saddle point comparisons among the molecules studied. The location of the transition state can be validated by a vibrational frequency calculation to show that there is a unique saddle point, based on the criterion that there is a single negative eigenvalue (first-order saddle point). This test was carried out for each transition state identified using the NEB and DIMER methods. Finally, the intrinsic reaction coordinate (IRC) can be calculated starting from the transition state and descending in both directions toward the reactant and the product. If the final structures at the end of the IRC resemble the reactant and product and the saddle point is unique, the transition state is validated. This method is robust, but it does not guarantee that the saddle point is unique.

The statistical mechanical corrections to the thermodynamic energies and the rate constants were calculated using the computer program stat_mech_rate written by Bartolotti. This computer program takes as input the generated molecular structure coordinates, energy gradients and hessian for the reactant molecules, product molecules and transition state. It uses this information to calculate the thermodynamic quantities (such as entropy, enthalpy, Gibbs energy and equilibrium constant) and rate constant using conventional transition state theory. [32] The atomic masses are used to generate the translational partition function which is based on a cubic box. The rotational partition function is constructed from the moments of inertia (obtained from the optimized molecular structure). Since the excited states are well separated from the ground state, the electronic partition function is taken as the degeneracy of the ground state. The harmonic vibrational frequencies are determined from the numerically calculated hessian matrix generated by $\mathrm{DMol}^{3}$. The program stat_mech_rate projects out the translational and rotational degrees of freedom from the hessian matrix and then performs the normal mode analysis to obtain the harmonic vibrational frequencies. These terms are then used to compute the molecular partition functions, from which equilibrium constants and transition state theory rate constants can be calculated following established methods. [33] For the transition states, the vibrational frequency along the reaction coordinate is imaginary (negative force constant) and it is not used in the construction of the vibrational partition function. This imaginary frequency is used to calculate a simple tunneling correction to the rate constant using the Wigner formula. 
[34] The significance of this correction for the calculation at hand is found in the discussion section.

The DFT calculations were compared to both MP2 and CC2 [35-37] calculations carried out using TURBOMOLE. [38] using a SVP basis set. [39] The CC2 method is a second order perturbation theory treatment of the coupled cluster operator. [40] The correlation energy obtained from CC2 calculations is mainly applicable to excited state corrections, although it should have ground state value as well. This comparison presented extends therefore provides interesting insight into the difference between MP2 and CC2. [40, 41]

The COSMO dielectric continuum model was employed in order to obtain an estimate of solvent effects. [42] The calculations were carried out for a dielectric constant of $\varepsilon=37$, which would be the value for acetonitrile. This is the most likely polar solvent. The value actually changes relatively little above $\varepsilon=37$, since the reaction field saturates at high field and is within ca. $85 \%$ of its final value by the time $\varepsilon=10$.

DFT methods are well suited to quantitative study of the effects of local differences in electron density on reactivity. We have also calculated Fukui function [43-45] (for $\Delta \mathrm{N}=0.2$ ) for each of the reactions,

$$
f(r)=\left[\frac{\partial \rho(r)}{\partial N}\right]_{V(r)}
$$

The global softness was calculated using the standard approach [46]

$$
S=\frac{1}{\eta}=\frac{2}{E_{L U M O}-E_{\text {НОMO }}}
$$

Using these two quantities we have examined the effects of local softness and the difference in the Fukui function between ground and transition states to decompose the thermodynamic trends into local density effects. [12]

\section{Results}


The structures of the geometry optimized reactants all have a $\mathrm{HX}\left(\right.$ or $\left.\mathrm{H}_{2} \mathrm{O}\right)$ molecule orthogonal to the propene $\pi$-bond with the hydrogen atom directed towards $\pi$-bond as shown in Figure 1. Their energies are reported in Hartrees in Table S1 of the Supporting Information. This type of hydrogen bonding pattern has been characterized for many molecules interacting with alkenes and alkynes. [47-49] Using this starting point and either 1- or 2-X propane as the product, the NEB calculations were run for approximately 70 iterations until the convergence criteria were met. The 30 geometries used to construct the NEB define a reaction path, which has a distinct maximum in each case (see Figure S1). The results from the converged NEB calculations resulted in a transition state for each of the reaction paths studied. The calculated binding energies of the transition states were obtained using the program DIMER (Table 5). The structures of the Markovnikov and anti-Markovnikov transition states identified by DIMER are shown in Figures 2 and 3, respectively.

The important distances in the transition states for both the M and AM pathways are shown in Tables 3 and 4. A C-H bond is in various stages of formation in the transition state due to the electrophilic attack of the $\mathrm{H}$ atom in $\mathrm{HX}$. The $\mathrm{H}-\mathrm{X}$ bond length increases in the transition state as $\mathrm{HBr}>\mathrm{HCl}>\mathrm{HF}>\mathrm{H}_{2} \mathrm{O}$, which can be attributed in part to the increase in ionic radius for the large halogens and in part to the increase in the acid dissociation constant. Based on the bond lengths in Tables 3 and 4 it appears that the TS structures are closer to the product structures for the $\mathrm{M}$ than for the AM pathway. Both the $\mathrm{C}-\mathrm{H}$ and $\mathrm{C}-\mathrm{X}$ bonds are shorter for the $\mathrm{M}$ than for the AM TS structures. The greater the anionic character of $X$, the greater the stabilization of the carbocation in the transition state, which is evident by the structure of the propenyl fragment in Figure 2. A crucial structural difference between the M and AM transition states is found in the $\mathrm{H}-\mathrm{X}$ bond length. In the M pathway this bond is quite long, indicating that the starting molecule is nearly dissociated. However, in the AM pathway, the $\mathrm{H}-\mathrm{X}$ bond length is $<0.1 \AA$ greater than in the reactant structure. This observation shows that the HX molecule is not significantly dissociated in the transition state for the AM pathway.

The validation of the transition state is presented in the intrinsic reaction coordinate (IRC) calculations shown in Figure 4. The structures produced by the IRC method following the normal mode coordinate and gradient to the reactant and product are similar to the reactant and product starting structures. The IRC calculation validates the transition states located using this NEB. The raw differences in the binding energies show a trend that the transition state energy 
increases relative to the reactant state energy for the series $\mathrm{HOH}>\mathrm{HF}>\mathrm{HCl}>\mathrm{HBr}$. For $\mathrm{HBr}$, $\mathrm{HCl}$ and $\mathrm{HF}$ the raw difference in binding energies predicts a lower transition state energy for the M pathway than for the AM pathway (Table 5). However, $\mathrm{HOH}$ has a smaller transition energy for the anti-Markovnikov mechanism based only on the energy calculated using the NEB and DIMER combined methods. This apparent reversal of the ordering of $\mathrm{M}$ and $\mathrm{AM}$ for $\mathrm{HOH}$ is mitigated by the changes in vibrational mode frequency and the effects of the zero-point contribution to the energy as shown in Table 1 . The calculated rate activation energy and rate constant that are used to correct for all kinematic effects (including rotational and vibrational partition functions) follows the trend $\mathrm{E}_{\mathrm{a}}(\mathrm{M})<\mathrm{E}_{\mathrm{a}}(\mathrm{AM})$ for all species (Table 1). When these factors are included, the calculated rate constants show a general increasing trend in the order $\mathrm{H}_{2} \mathrm{O}<\mathrm{HF}<\mathrm{HCl}<\mathrm{HBr}$, but the ratio of the rate constants $\mathrm{k}(\mathrm{M}) / \mathrm{k}(\mathrm{AM})$ is approximately $10^{5}$ for the entire series (Table 1). Thus, we see the importance of including the partition function in the calculated activation energy and rate constant. The corrections to the thermodynamic parameters are less critical than the kinetic parameters. However, one sees in Table 2 that when the free energy is calculated using the partition function, there is a general trend towards decreasing magnitude of $\Delta \mathrm{G}^{\mathrm{o}}$ for the reaction. The decrease is approximately $1 \mathrm{kcal} / \mathrm{mol}$ for $\mathrm{HBr}>\mathrm{HCl}>$ $\mathrm{HF}$, but drops by nearly $5 \mathrm{kcal} / \mathrm{mol}$ for $\mathrm{H}_{2} \mathrm{O}$ relative to the other species. Despite these differences, the equilibrium constant ratio $\mathrm{K}(\mathrm{M}) / \mathrm{K}(\mathrm{AM}) \sim 200$ on average for the series.

The activation energies and reaction internal energies obtained by both $\mathrm{CC} 2$ and MP2 calculations presented in Tables 6 and 7 can compared to the values in Table 5 using DFT without the inclusion of the correction based on the partition function (see Tables 1 and 2). The trends are similar and the activation energy increases in the order $\mathrm{HBr}<\mathrm{HCl}<\mathrm{HF}<\mathrm{H}_{2} \mathrm{O}$ for all methods. The DFT calculation shows a much larger difference in the activation energy in the series of electrophiles (Table 5). The anti-Markovnikov has a greater activation energy than the Markovnikov reaction in all cases except $\mathrm{H}_{2} \mathrm{O}$ in the DFT calculation (Table 5). However, the order of $\mathrm{M}$ and $\mathrm{AM}$ for $\mathrm{H}_{2} \mathrm{O}$ calculated by DFT follows the trend of the other methods when the partition function is included (Table 1).

In order to understand the origins of the structural and energetic trends described above, we can examine the charge distribution in the transition state in order to determine the correlation of the electronic structural change due to the polarization of the adding group with the reaction rate. The central carbon, $\mathrm{C} 2$, in the M pathway has a positive Hirshfeld charge that 
increases in the order $\mathrm{Br}>\mathrm{Cl}>\mathrm{F}>\mathrm{OH}$ (Table 9), while the $\mathrm{C} 1$ carbon carries a larger negative charge. The halogens (and $\mathrm{O}$ atom in $\mathrm{H}_{2} \mathrm{O}$ ) each carry a negative charge, which increases in the same order. Of course, the $\mathrm{H}$ atom transferred in the process carries a positive charge. Thus, the transition state consists of an $\mathrm{H}^{+} \mathrm{X}^{-}$dipole, which induces a dipole across the $\pi$-bond, which is either $\mathrm{C}^{-} \mathrm{C}^{+}$or $\mathrm{C}^{+} \mathrm{C}^{-}$for the $\mathrm{M}$ or $\mathrm{AM}$ mechanism, respectively. The combined charge distribution is a quadruple, which has an increasing magnitude for the larger halogens and is significantly larger for $\mathrm{M}$ than AM addition. This is illustrated schematically in Figure 5. The trends observed for the AM pathway are similar, but the polar nature of the transition state is significantly smaller. For example, an explicit calculation of the dipole moment for addition of $\mathrm{HBr}$ in the transition state gives 6.2 and 5.2 Debye for the M and AM pathways, respectively. For $\mathrm{HCl}$ the values are 5.8 and 5.0 Debye, respectively, as would be predicted based on the relative magnitude of the Hirshfeld charges (Table 9).

The change in the local softness, $\Delta \mathrm{s}_{\mathrm{k}}$, between the TS and GS shown Table 10 for the both $\mathrm{AM}$ and $\mathrm{M}$ reactions shows the same trend $\mathrm{Br}>\mathrm{Cl}>\mathrm{F}>\mathrm{OH}$. The Hirschfeld charges and Fukui function for each species studied is given Tables S8 and S9, respectively, of the Supporting Information. The trend in local softness can be anticipated from the increasing polarizability of the halogens $\mathrm{Br}>\mathrm{Cl}>\mathrm{F}$. The change in softness in the TS is larger for the $\mathrm{M}$ pathway then the $\mathrm{AM}$ pathway for $\mathrm{Br}$ and $\mathrm{Cl}$. The different in the total differential softness function between the central and terminal atom $\Delta \mathrm{s}_{2}-\Delta \mathrm{s}_{1}$ is largest for $\operatorname{Br}$ (6.29 vs. 3.40) while for $\mathrm{Cl}$ it is more nearly equal (4.56 vs. 3.26). We observe a qualitative change of $\mathrm{F}$ and $\mathrm{OH}$, in which the $\Delta \mathrm{s}_{2}$ is actually larger for the AM pathway than for the M pathway. However, the $\Delta \mathrm{s}_{2}-$ $\Delta s_{1}$ difference is still larger for $\mathrm{M}$ by a small margin for $\mathrm{F}(2.00 \mathrm{vs} 1.92)$. For $\mathrm{OH}$ the difference is actually larger for the AM pathway (2.66 vs. 2.70).

\section{Discussion}

The Markovnikov (M) product of addition to an alkene is the preferred product for an ionic mechanism, which is relevant when the attacking group is a strong acid. DFT calculations show that the $\mathrm{M}$ product is preferred for all of the reactants studied despite enormous differences in the acidity of the adding species. $\mathrm{HBr}$ and $\mathrm{HCl}$ are strong acids. $\mathrm{HF}$ is a weak acid with a $\mathrm{pK}_{\mathrm{a}}$ $\sim 3.1$ and $\mathrm{H}_{2} \mathrm{O}$, of course, has a $\mathrm{pK}_{\mathrm{a}}=15.7$. One can conclude that a sequential mechanism 
(Figure 2) is operative in the Markovnikov addition of all four molecules studied. In this case, the sequential mechanism refers to the fact that the $\mathrm{H}-\mathrm{X}$ bond is broken prior to the formation of the $\mathrm{C}-\mathrm{X}$ bond. The alternative is a concerted mechanism in which $\mathrm{H}^{+}$and $\mathrm{X}^{-}$add simultaneously across the $\pi$-bond.

The results suggest that the transition state is not concerted, which explains why acid catalysis can lower the energy of the transition state. Acid catalysis is well known in the electrophilic addition of $\mathrm{H}_{2} \mathrm{O}$ across the $\pi$-bond. One can examine two aspects of reactivity, which are the formation of a carbocation and the hydrogen ion transfer from the acid to the alkene both of which are manifestations of the polar transition state. However, the acid catalysis in this case is dominated by the electrophile $\mathrm{HX}$. With the exception of $\mathrm{H}_{2} \mathrm{O}$ the $\mathrm{HX}$ electrophiles are all sufficiently acidic that it would be difficult to find an extrinsic catalyst. Thus, the situation differs from studies where base catalysis depends on explicit solvent. [50] While catalysis of addition by $\mathrm{H}_{2} \mathrm{O}$ is possible, the solvents that might permit (e.g. methanol) this are beyond the scope of the present study.

Many previous computational approaches to electrophilic additions have focused on energetic considerations.[10] Our goal is to show the application of DFT methods to determine the polar character of the transition state as well as its energy. Using tabulated enthalpies of formation, the enthalpy of reaction for the formation of 1-propanol and 2-propanol by the hydration of propene are predicted to be $-8.82 \mathrm{kcal} / \mathrm{mol}$ and $-12.4 \mathrm{kcal} / \mathrm{mol}$, respectively. These values compare well to the calculated values of -8.02 and $-11.7 \mathrm{kcal} / \mathrm{mol}$ for 1 - and 2-propanol, respectively, based on the DFT method used here. Based on these values, it would be expected that the formation of 2-propanol would be thermodynamically favored, which is consistent with the major product predicted by Markovnikov's rule. Industrially, 2-propanol is produced using propene as a starting material, often by direct hydration in the presence of an acid catalyst. The direct hydration of propene, depending on reaction conditions and catalyst used, has up to a $96 \%$ selectivity for 2-propanol. Similar agreement is found for reactions of $\mathrm{HCl}$ and $\mathrm{HBr}$ with propene demonstrating the largest discrepancy found for the bromopropanes. The experimental heats of reaction for 1- and 2-bromopropane are -25.9 and $-27.0 \mathrm{kcal} / \mathrm{mol}$, compared to calculated values of -14.2 and $-17.2 \mathrm{kcal} / \mathrm{mol}$, respectively. For 1- and 2-chloropropane, the experimental (calculated) values are $-13.9(-12.5)$ and -17.8 (-16.0) kcal/mol, respectively. The computational results obtained in this study agree well with previous studies on similar molecules. [51, 52] 
The mechanism consistent with the DFT calculations involves proton transfer from HX to either $\mathrm{C} 1$ or $\mathrm{C} 2$ of 1-propene (M or AM, respectively). The analysis of the charge distribution in the transition state suggests that the dipole moment of $\mathrm{H}-\mathrm{X}$ results in a corresponding dipole moment $\mathrm{C} 1-\mathrm{C} 2$, whose sign depends on the whether the result is M or AM. The association of the two dipole moments creates a quadrupolar transition state (Figure 5). The negative charge in a carbon atom arises because of the protonation of the carbon atom. These observations suggest that the origin of the stabilization involves core orbitals of the two carbons rather than hyperconjugation as is often suggested as the mechanism of carbocation stability. [22] While hyperconjugation clearly exists (or can exist in the proper conformation) the positive charges on the $\mathrm{H}$ atoms are consistent with a stabilization of the product adduct, in which the $\mathrm{X}^{-}$ion has formed a bond with the carbon atom rather than a stabilization of the carbocation in the transition state.

A recent study presents the provocative hypothesis that there is a correlation between the core electron energies of the carbon atoms and the local reactivity.[53] The experimental trend in the $1 \mathrm{~s}$ ionization energies of ethene, propene and 2-methylpropene correlates with the rate of addition of electrophiles, HX. The idea that the ionization of the core is related to the reactivity of the valence orbitals does not follow common assumptions about the importance of the frontier orbitals. The conclusion of the study is that the ground state properties are most important for defining reactivity. $[6,7,12,54]$ The hypothesis of ground state properties as the foundation of reactivity is consistent with the quadrupolar transition state, since the addition of the $\mathrm{H}$ atom will occur in such a way as to create the most stable $\mathrm{C}-\mathrm{H}$ bond. That bond is also dipolar and we can see the trend in the calculation that the bond is more stable for $\mathrm{C} 1$ than $\mathrm{C} 2$ in the molecules studied.

In order to understand this relationship more deeply we invoke the philosophy of the DFT method, which states that the electron density should be used not only for the energy calculation, but also for evaluation of molecular properties. We have used DFT to provide the energies, vibrational partition function, and Fukui function each of which gives an aspect needed to understand why $\mathrm{H}_{2} \mathrm{O}$ addition to propene follows the Markovnikov trend. DFT calculations provide the equilibrium constants and transition state theory rate constants defined in Eqn. 5:

$$
\mathrm{k}_{\mathrm{corr}}=\kappa(\mathrm{T}) \mathrm{k}_{\mathrm{TST}}(\mathrm{T})
$$


where $\kappa(T)$ is the tunneling correction[34] given by

$$
\kappa(T)=1+\frac{1}{24}\left[\frac{h v_{s}}{k_{B} T}\right]^{2}\left(1+\frac{k_{B} T}{E_{a}}\right)
$$

In this definition, $v_{\mathrm{s}}$ refers to the mode that is along the transition state coordinate. In the case of the Markovnikov addition, that coordinate has a large component of $\mathrm{X}-\mathrm{H}$ stretching, where $\mathrm{X}=$ $\mathrm{Br}, \mathrm{Cl}, \mathrm{F}$ or $\mathrm{OH}$. Because the transition state has an imaginary frequency, it is not included in the vibrational partition function at the transition state. We write the transition state rate constant as:

$$
\mathrm{k}_{\mathrm{TST}}(\mathrm{T})=\frac{\mathrm{k}_{\mathrm{B}} \mathrm{T}}{\mathrm{h}} \exp \left\{-\frac{\Delta \mathrm{G}_{\mathrm{TST}}^{\ddagger}}{\mathrm{k}_{\mathrm{B}} \mathrm{T}}\right\}
$$

The transition state rate constant can be calculated using inputs from either experiment or the calculation based on the reactant and transition state partition functions are well known and are given in the Supporting Information for completeness. We have used the inputs from DFT for the calculation of these quantities, since these differ by less than $2 \%$ from experiment. [55]

The $\mathrm{H}-\mathrm{X}$ stretching vibrations in the $\mathrm{q}^{\mathrm{HX}}$ partition function have the value $\mathrm{HF}\left(3987 \mathrm{~cm}^{-1}\right)>$ $\mathrm{H}_{2} \mathrm{O}\left(3718 \mathrm{~cm}^{-1}\right)>\mathrm{HCl}\left(2950 \mathrm{~cm}^{-1}\right)>\mathrm{HBr}\left(2585 \mathrm{~cm}^{-1}\right)$. The barrier will be effectively lowered by the conversion of these ground state vibrations into the softer bond breaking mode that becomes the saddle point coordinate (see Supporting Information). The calculation shows that the transition state geometry of the $\mathrm{H}-\mathrm{X}$ bonds along the AM pathway is essentially the same as the ground state. On the other hand, the $\mathrm{H}-\mathrm{X}$ bonds are significantly elongated for the M pathway, making the transition state partition function significantly weighted towards a saddle point along the stretching mode. The energetic consequences are significantly greater for $\mathrm{HF}$ and $\mathrm{H}_{2} \mathrm{O}$, which explains their barrier lowering along the M pathway. Since the frequency of the vibrational mode along the transition state coordinate increases in the order $\mathrm{HBr}<\mathrm{HCl}<\mathrm{H}_{2} \mathrm{O}<\mathrm{HF}$ we can understand that the activation barrier is lowered more for $\mathrm{HF}$ and $\mathrm{HOH}$ when the tunneling corrected transition state theory is employed, which explains the agreement with the experimental Markovnikov trends when the transition state approach is used. These corrections are implied in the DFT calculations and we have not used any other inputs or data to arrive at these conclusions. The importance of this insight is that the $\mathrm{X}-\mathrm{H}$ stretching mode that gives rise to these effects is the bond breaking coordinate that gives rise to proton transfer, which in turn is the event that gives to charge transfer necessary to explain the excited state dipole character. The 
polar nature of the transition state in M pathway is correlated with a significant elongation of the $\mathrm{X}-\mathrm{H}$ bond in the transition state. This is a major structural difference vis-à-vis the AM pathway. The reason that the $\mathrm{X}-\mathrm{H}$ is crucial is that this elongation is coupled to proton transfer to the terminal carbon to create a polar transition state. The (partial) protonation of the terminal carbon atom simultaneously stabilizes $\mathrm{X}^{-}$and the allyl carbocation, hence it creates a polar transition state. COSMO results in a significant lowering of the activation barrier, which is greatest for the most polar transition state, i.e. $\mathrm{HBr}>\mathrm{HCl}>\mathrm{HF}>\mathrm{H}_{2} \mathrm{O}$. Actually, $\mathrm{H}_{2} \mathrm{O}$ is destabilized by solvation because it is relatively less polar than the hydrohalides. [42]

One can use the Fukui function and local softness concept to decompose the contributions further. The goal of this analysis is to use quantitative aspects of DFT to determine the extent to which the transition state is stabilized by soft-soft interaction and the extent to which local charge displacement. These concepts, of course, were derived with the Fukui frontier orbital as the basis so they are a measure of the overlap of those crucial orbitals in the transition state. Analysis using the regional softness approach

$$
s_{i}(r)=f_{i}(r) S
$$

in terms of the difference between the reactant and transition states gives rise to two contributions,

$$
\Delta s_{i}(r)=\Delta f_{i} S^{0}+f_{i}^{\ddagger} \Delta S
$$

In this analysis $f(r)$ is the Fukui function, which is a measure of the local density change for a given global electron density difference (which is $\Delta \mathrm{N}=0.2$ in our calculation). The general softness function, $S=2 /(I-A)$, where I and A are the ionization potential and electron affinity, respectively. The softness function is a general or delocalized measure of how polarizable the molecule is. The Fukui function helps us to understand the change in the total softness in terms of the local effects that govern regioselectivity. The Fukui function has a larger negative value on the less reactive carbon atom. The difference is between the transition and reactant states such that, $\Delta S=S^{\ddagger}-S^{0}$ and $\Delta f_{i}=f_{i}^{\ddagger}-f_{i}^{0} . \Delta S$ is the global reactivity function, 
while $\Delta f_{i}$ is a local reactivity function, i.e. a selectivity function. The analysis of how the Fukui function defines the local softness involves separate consideration of the two terms that comprise Eqn. 4. The largest term is $f_{i}(r) \Delta S$, which represents the change in softness modified by the overall Fukui function of the TS. The second term, $\Delta f_{i}(r) S$, reinforces the value of the first term, but reflects the change in the local electron density between the TS and GS, which is significantly larger for the $\mathrm{M}$ than the AM pathway for all reactants.

There is a general trend across all systems studied for $\Delta S$ to be larger for the $\mathrm{M}$ than the AM reaction. However, $\Delta S$ decreases significantly in the order $\mathrm{HBr}>\mathrm{HCl}>\mathrm{H}_{2} \mathrm{O}>\mathrm{HF}$ while the local selectivity function $\Delta f_{i}$ is quite similar for all four of the $\mathrm{M}$ reactions. The overall reactivity function, $\Delta s_{i}$, has a larger difference between $\mathrm{C} 1$ and $\mathrm{C} 2$ for the $\mathrm{M}$ than for the AM reaction for reactant except $\mathrm{HF}$ where the $\mathrm{M}$ and $\mathrm{AM}$ are nearly the same. This fact indicates that the $\mathrm{M}$ transition state will be more polar than the AM transition state in all cases except $\mathrm{HF}$, where the polarity is predicted to be nearly equal. This analysis agrees with the Hirshfeld charges in Table 9. The analysis of the quadrupole in the transition state agrees with the difference in $\Delta s_{i}$ for $\mathrm{C} 1$ and $\mathrm{C} 2$. Both methods of analysis indicate that there is a larger charge asymmetry in the M transition state than in the AM transition state. Another measure of the polar nature of the transition state is the charge difference between $\mathrm{H}$ and $\mathrm{X}$, which also contributes to the quadrupole. The difference is larger for M than AM for all of the species except HF where the difference is nearly equal. Hence, the Fukui/softness analysis in Table 10 reinforces and more precisely quantifies the quadrupolar nature of the transition state one obtains from the charge partitioning analysis shown in Table 9. These conclusions agree with the solvent effect on the transition state calculated using COSMO, which shows that polar solvents lower the activation energy, which is an expected outcome for a polar transition state. The fact that electrophilic addition of $\mathrm{H}_{2} \mathrm{O}$ follows the Markonikov trend can be understood succinctly as follows. $\mathrm{H}_{2} \mathrm{O}$ is a strongly polar molecular, which gives rise selectivity that is as great as $\mathrm{HCl}$ or $\mathrm{HBr}$. However, the low acidity of $\mathrm{H}_{2} \mathrm{O}$ means that its global reactivity is much lower that for $\mathrm{HCl}$ or $\mathrm{HBr}$ as indicated by the softness function. [56]

The regioselectivity for $\mathrm{H}_{2} \mathrm{O}$ addition to 1-propene calculated by DFT methods is in agreement with the known reactivity of $\mathrm{H}_{2} \mathrm{O}$ with 1-propene in the industrial production of 2propanol (isopropanol). The direct process involves hydration of propene without intermediacy of an acid, which is a feasible process provided the propene is quite pure. [57] It is interesting to 
note that the process using $\mathrm{H}_{2} \mathrm{SO}_{4}$ instead of $\mathrm{H}_{2} \mathrm{O}$ was used prior to 1951 because it was necessary to boost the reactivity under conditions in which the propene was not very pure. As expected, the factors discussed above that favor the Markovnikov mechanism can be mitigated by use of a radical initiator to cause the reaction to proceed via a radical mechanism. This is done in some cases to produce 1-propanol from propene and $\mathrm{H}_{2} \mathrm{O}$. [13, 58-60] Based on the calculated thermodynamic and kinetic parameters, we have established that one can use the DFT methods with the ancillary analysis tools of the Fukui and softness functions to estimate the significance of catalytic agents on the reactivity and the predict potential changes in regioselectivity linked to the quadrupolar nature of the transition state. Less is known experimentally about HF, but the calculation was included for sake of completeness. HF is predicted to follow the M pathway as well.

\section{Conclusion}

Markovnikov (M) and anti-Markovnikov (AM) reactions have been studied in depth for decades, with extensive support behind the theory that $\mathrm{M}$ electrophilic addition reactions are favored over AM reactions. There are numerous studies that support the M mechanism that the process involves transient formation of a carbocation and that the $\mathrm{X}^{-}$nucleophile will add to the most substituted carbon in the olefin, i.e. to the carbon that has the most stable carbocation in the transition state. In this study, we have focused on a complementary aspect of this reaction, which is the role of the acidity of the electrophile adding across the $\pi$-bond. The reactivity is relatively clear in the case of strong acids such as $\mathrm{HBr}$ and $\mathrm{HCl}$, but the experimental observables are more difficult to reconcile with theory for $\mathrm{HF}$ and $\mathrm{H}_{2} \mathrm{O}$. We are particularly interested in $\mathrm{H}_{2} \mathrm{O}$, which is important in industrial processes and has some similarity with photohydration observed in nucleic acids. [1] It is important to understand that factors that permit hydration to occur as a ground state reaction and distinguish those from the excited state hydration observed in pyrimidines.

This study shows the utility of the NEB approach for locating transitions implemented using DFT for energy calculations. The comparison with post-HF methods validates the use of DFT for energy, structure and vibrational frequency calculations. However, the energetic calculation of the transition state required consideration of the partition function in order to 
obtain agreement for the $\mathrm{H}_{2} \mathrm{O}$ addition reaction. The contribution of the partition function is dominated by the vibrational partition function and indeed the energy of the transition is lowered by an amount roughly equal to the zero-point-energy of the stretching vibration for each molecule. The trend in the vibrational frequencies is $\mathrm{HF} \sim \mathrm{H}_{2} \mathrm{O}>\mathrm{HCl}>\mathrm{HBr}$, which accounts specifically for the lowering of the $\mathrm{H}_{2} \mathrm{O}$ activation energy for M relative to AM. When all of the factors are included we can explain the low reactivity of $\mathrm{H}_{2} \mathrm{O}$ relative to $\mathrm{HCl}$ and $\mathrm{HBr}$ as a consequence of the activation energy of $\mathrm{H}_{2} \mathrm{O}$, which is significantly greater than either $\mathrm{HCl}$ or $\mathrm{HBr}$. However, the analysis of the transition state energy does not explain the similarity in the regioselectivity trends.

The key to regioselectivity is found in the polar nature of the transition state. In order to understand this aspect we have used the Fukui and molecular softness functions, which give us the local selectivity (due to polarizability) and the overall reactivity, respectively. This local dipolar term arising from the local selectivity $\left(\Delta f_{i} S^{0}\right)$ is the most important for $\mathrm{H}_{2} \mathrm{O}$ since the overall reactivity $\left(f_{i}^{\ddagger} \Delta S\right)$ for $\mathrm{H}_{2} \mathrm{O}$ is relatively small compared to $\mathrm{HCl}$ or $\mathrm{HBr}$. In fact, this difference in overall reactivity applies to both M and AM mechanisms. Moreover, the difference in $f_{i}^{\ddagger} \Delta S$ between $\mathrm{M}$ and $\mathrm{AM}$ is not very large for $\mathrm{H}_{2} \mathrm{O}$ compared to the strong acids. Instead, the local selectivity $\Delta f_{i} S^{0}$ suggests that it is the ability of $\mathrm{H}_{2} \mathrm{O}$ to add across the $\pi$-bond to create a quadrupolar transition state in a manner that resembles the strong acids. The polarization of the transition state stabilizes the carbocation, which both lowers the barrier and makes it susceptible to solvent effects. The COSMO solvation model predicts that polar solvents will lower the barrier proportional to the polarity of the transition state. In summary, DFT methods can provide detailed insight into why $\mathrm{H}_{2} \mathrm{O}$ follows the Markovnikov trend of regioselective addition to the most substituted carbon atom.

Acknowledgment. We gratefully acknowledge support from the NSF through grant 0958311 , which supported the calculations conducted on the Advanced ARC cluster, the High Performance Cluster at North Carolina State University as well as the Center of Applied Computational Studies at East Carolina University for providing computational resources to support some of the calculations reported in this paper. 


\section{References}

[1] S. Franzen, B. Skalski, L. Bartolotti, B. Delley, Phys. Chem. Chem. Phys., 16 (2014) 2016420174.

[2] Y.L. Ding, Z.Z. Yang, J. Mol. Struct.-Theochem, 944 (2010) 105-109.

[3] P. Horrillo-Martinez, K.C. Hultzsch, A. Gil, V. Branchadell, Eur. J. Org. Chem., (2007) 3311-3325.

[4] H.X. Li, M.W. Wen, G. Lu, Z.X. Wang, Dalton Trans., 41 (2012) 9091-9100.

[5] J.V. Burda, J.S. Murray, A. Toro-Labbe, S. Gutierrez-Oliva, P. Politzer, J. Phys. Chem. A, 113 (2009) 6500-6503.

[6] C.H. Suresh, N. Koga, S.R. Gadre, J. Org. Chem., 66 (2001) 6883-6890.

[7] Z.Z. Yang, Y.L. Ding, D.X. Zhao, Chemphyschem, 9 (2008) 2379-2389.

[8] W.F.K. Schnatter, D.W. Rogers, A.A. Zavitsas, Chem. Eur. J., 21 (2015) 10348-10361.

[9] J. Guo, P. Teo, Dalton Trans., 43 (2014) 6952-6964.

[10] L. Meneses, A. Araya, F. Pilaquinga, R. Contreras, P. Fuentealba, Chem. Phys. Lett., 446 (2007) 170-175.

[11] J. Padmanabhan, R. Parthasarathi, V. Subramanian, P.K. Chattaraj, J. Mol. Struct.Theochem, 804 (2007) 17-20.

[12] A. Aizman, R. Contreras, M. Galvan, A. Cedillo, J.C. Santos, E. Chamorro, J. Phys. Chem. A, 106 (2002) 7844-7849.

[13] J. Li, Z. Quin, H. Xu, M. Dong, J. Dong, J. Wang, Ind. Eng. Chem. Res., 46 (2007) 90009005.

[14] F.R. Mayo, C. Walling, Chem. Rev., 27 (1940) 351-412.

[15] R.K. Hessley, J. Chem. Ed., 77 (2000) 794-797.

[16] D. Sheppard, R. Terrell, G. Henkelman, J. Chem. Phys., 128 (2008).

[17] G. Henkelman, H. Jonsson, J. Chem. Phys., 111 (1999) 7010-7022.

[18] G. Henkelman, H. Jonsson, J. Chem. Phys., 113 (2000) 9978-9985.

[19] G. Henkelman, B.P. Uberuaga, H. Jonsson, J. Chem. Phys., 113 (2000) 9901-9904.

[20] D.H. Mei, L. Xu, G. Henkelman, J. Catal., 258 (2008) 44-51.

[21] D. Sheppard, G. Henkelman, J. Comp. Chem., 32 (2011) 1769-1771.

[22] N. Otero, M. Mandado, J. Comp. Chem., 33 (2012) 1240-1251. 
[23] B. Delley, J. Chem. Phys., 92 (1990) 508-517.

[24] B. Delley, J. Chem. Phys., 113 (2000) 7756-7764.

[25] B. Delley, J. Phys. Chem. A, 110 (2006) 13632-13639.

[26] J.P. Perdew, K. Burke, Y. Wang, Phys. Rev. B: Condens. Matter, 54 (1996) 16533-16539.

[27] J.P. Perdew, Y. Wang, Phys. Rev. B, 45 (1992) 13244-13249.

[28] B.J. Lynch, D.G. Truhlar, J. Phys. Chem. A, 105 (2001) 2936-2941.

[29] A. Heyden, A.T. Bell, F.J. Keil, J. Chem. Phys., 123 (2005).

[30] R.A. Olsen, G.J. Kroes, G. Henkelman, A. Arnaldsson, H. Jonsson, J. Chem. Phys., 121 (2004) 9776-9792.

[31] H.B. Schlegel, J. Comp. Chem., 3 (1982) 214-218.

[32] W.H. Miller, N.C. Handy, J.E. Adams, J. Chem. Phys., 72 (1980) 99-112.

[33] D.A. McQuarrie, Statistical Mechanics, Harper and Row, New York, (1976).

[34] E. Wigner, Z. Phys. Chem. B, 19 (1932) 203-216.

[35] K. Hald, C. Hattig, D.L. Yeager, P. Jorgensen, Chem. Phys. Lett., 328 (2000) 291-301.

[36] C. Hattig, K. Hald, Phys. Chem. Chem. Phys., 4 (2002) 2111-2118.

[37] K. Hald, P. Jorgensen, O. Christiansen, H. Koch, J. Chem. Phys., 116 (2002) 5963-5970.

[38] C. Hattig, F. Weigend, J. Chem. Phys., 113 (2000) 5154-5161.

[39] A. Schäfer, H. Horn, R. Ahlrichs, J. Chem. Phys., 97 (1992) 2571.

[40] O. Christiansen, H. Koch, P. Jorgensen, Chem. Phys. Lett., 243 (1995) 409-418.

[41] C. Moller, M.S. Plesset, Phys. Rev., 46 (1934) 0618-0622.

[42] A. Klamt, G. Schüürmann, J. Chem. Soc., Perkin Trans, 2 (1993) 799-805.

[43] K. Fukui, Science, 218 (1982) 747-754.

[44] R.G. Parr, W.T. Yang, J. Am. Chem. Soc., 106 (1984) 4049-4050.

[45] Y. Li, J.N.S. Evans, J. Am. Chem. Soc., 117 (1995) 7756-7759.

[46] R.G. Parr, R.G. Pearson, J. Am. Chem. Soc., 105 (1983) 7512-7516.

[47] W.G. Read, W.H. Flygare, J. Chem. Phys., 76 (1982) 2238-2246.

[48] J.A. Pople, M.J. Frisch, J.E. Delbene, Chem. Phys. Lett., 91 (1982) 185-189.

[49] M.J. Frisch, J.A. Pople, J.E. Delbene, J. Chem. Phys., 78 (1983) 4063-4065.

[50] F.M. Bickelhaupt, E.J. Baerends, N.M.M. Nibbering, T. Ziegler, J. Am. Chem. Soc., 115 (1993) 9160-9173.

[51] R. Stolevik, K. Hagen, J. Mol. Struct., 352/353 (1995) 23-58. 
[52] C. Tanaka, J. Tanaka, K. Hirao, J. Mol. Struct. , 146 (1986) 309-327.

[53] L.J. Saethre, T.D. Thomas, S. Svensson, J. Chem. Soc.-Perkin Trans. 2, (1997) 749-755.

[54] M.P. Perez-Casany, I. Nebot-Gil, J. Sanchez-Marin, J. Phys. Chem. A, 104 (2000) 1072110730.

[55] G. Herzberg, D. van Nostrand Co., Inc., Princeton, New Jersey, (1950).

[56] P.K. Chattaraj, U. Sarkar, D.R. Roy, M. Elango, R. Parthasarathi, V. Subramanian, Indian J. Chem. A Inorg. Bio-Inorg. Phys. Theo. Anal. Chem., 45 (2006) 1099-1112.

[57] G.S.J. Lee, J.H. McCain, M.M. Bhasin, Synthetic Organic Chemicals. In: Kent, J.A., editor, Riegel's Handbook of Industrial Chemistry, 10th Ed.,

New York: Kluwer Academic/Plenum Publishers, Chapter 22 (2003) pp. 851-854.

[58] M. Beller, J. Seayad, A. Tillack, H. Jiao, Angew. Chem. Int. Ed., 43 (2004) 3368-3398.

[59] J. Zador, A. Jasper, J. Miller, Phys. Chem. Chem. Phys., 11 (2009) 11040-11053.

[60] A. Papa, Ullmann's Encyclopedia of Industrial Chemistry,, Weinheim: Wiley-VCH (2005). 


\section{Tables}

Table 1. Kinetic parameters for both Markovnikov and anti-Markovnikov reactions calculated using the statistical mechanical model based on the inputs from the DFT calculations. Units of $\mathrm{kcal} / \mathrm{mol}$ were used for $\mathrm{E}_{\mathrm{a}}$ and $\Delta \mathrm{H}^{\ddagger}$ and using of cal/mol-K were used for $\Delta \mathrm{S}^{\ddagger}$.

\begin{tabular}{|l|c|c|c|c|}
\hline Species & $\mathrm{E}_{\mathrm{a}}$ & $\Delta \mathrm{H}^{\ddagger}$ & $\Delta \mathrm{S}^{\ddagger}$ & $\ln (\mathrm{k})$ \\
\hline HBr M & 23.1 & 22.8 & -1.53 & -9.87 \\
\hline HBr AM & 30.0 & 29.7 & -4.15 & -22.7 \\
\hline HCl M & 27.9 & 27.7 & -1.75 & -18.1 \\
\hline HCl AM & 35.0 & 34.8 & -1.26 & -29.9 \\
\hline HF M & 34.4 & 33.8 & -6.14 & -30.6 \\
\hline HF AM & 41.6 & 40.9 & -6.35 & -42.8 \\
\hline HOH M & 44.1 & 43.2 & -8.50 & -47.7 \\
\hline HOH AM & 50.0 & 48.8 & -9.93 & -58.0 \\
\hline
\end{tabular}

Table 2. Thermodynamic parameters for both Markovnikov and anti-Markovnikov reactions calculated using the statistical mechanical model based on the inputs from the DFT calculations. Free energies and enthalpies and are given in units of kcal/mol. Entropies are given in entropy units of $\mathrm{cal} / \mathrm{mol}-\mathrm{K}$.

\begin{tabular}{|l|c|c|c|c|}
\hline Species & $\Delta \mathrm{G}^{\mathrm{o}}$ & $\Delta \mathrm{H}^{\mathrm{o}}$ & $\Delta \mathrm{S}^{\mathrm{o}}$ & $\ln (\mathrm{K})$ \\
\hline HBr M & -14.9 & -17.2 & -7.77 & 25.1 \\
\hline HBr AM & -12.0 & -14.2 & -7.42 & 20.3 \\
\hline HCl M & -13.7 & -16.0 & -7.75 & 23.1 \\
\hline HCl AM & -10.3 & -12.5 & -7.52 & 17.3 \\
\hline HF M & -13.3 & -13.6 & -0.935 & 22.5 \\
\hline HF AM & -5.77 & -7.75 & -6.62 & 9.74 \\
\hline HOH M & -8.37 & -11.7 & -11.1 & 14.1 \\
\hline HOH AM & -5.45 & -8.05 & -8.74 & 9.19 \\
\hline
\end{tabular}

Table 3. Markovnikov pathway transition state geometry. Bond lengths are given in $\AA$.

\begin{tabular}{|l|l|l|l|l|}
\hline $\mathrm{X}$ & $\mathrm{C}-\mathrm{X}$ & $\mathrm{C}-\mathrm{H}$ & $\mathrm{H}-\mathrm{X}$ & $\mathrm{C}-\mathrm{C}$ \\
\hline $\mathrm{Br}$ & 3.003 & 1.918 & 2.050 & 1.418 \\
\hline $\mathrm{Cl}$ & 2.720 & 1.233 & 1.855 & 1.412 \\
\hline $\mathrm{F}$ & 2.000 & 1.098 & 2.972 & 1.486 \\
\hline $\mathrm{OH}$ & 1.966 & 1.095 & 3.175 & 1.426 \\
\hline
\end{tabular}


Table 4. Anti-Markovnikov pathway transition state geometry. Bond lengths are given in $\AA$.

\begin{tabular}{|l|l|l|l|l|}
\hline $\mathrm{X}$ & $\mathrm{C}-\mathrm{H}$ & $\mathrm{C}-\mathrm{X}$ & $\mathrm{H}-\mathrm{X}$ & $\mathrm{C}-\mathrm{C}$ \\
\hline $\mathrm{Br}$ & 1.253 & 4.004 & 1.995 & 1.518 \\
\hline $\mathrm{Cl}$ & 1.269 & 3.000 & 1.836 & 1.516 \\
\hline $\mathrm{F}$ & 1.318 & 3.459 & 1.336 & 1.516 \\
\hline $\mathrm{OH}$ & 1.400 & 1.924 & 2.363 & 1.421 \\
\hline
\end{tabular}

Table 5. Difference energies $(\mathrm{kcal} / \mathrm{mol})$ of transition states and reaction enthalpies for

Markovnikov and anti-Markovnikov pathways calculated using DFT (PBE) without inclusion of statistical mechanical corrections.

\begin{tabular}{|r|r|r|r|r|r|r|r|r|}
\hline Species & Br M & Br AM & Cl M & Cl AM & F M & F AM & OH M & OH AM \\
\hline $\mathrm{E}_{\mathrm{a}}$ & 16.9 & 24.5 & 30.0 & 37.1 & 37.6 & 44.1 & 62.0 & 56.8 \\
\hline$\Delta \mathrm{U}_{\text {prod }}$ & -20.0 & -24.3 & -17.6 & -15.1 & -9.17 & -9.17 & -0.013 & -3.20 \\
\hline
\end{tabular}

Table 6. Calculated difference energies $(\mathrm{kcal} / \mathrm{mol})$ of the transition state and product for Markovnikov and anti-Markovnikov pathways using CC2.

\begin{tabular}{|r|r|r|r|r|r|r|r|r|}
\hline Species & Br M & Br AM & \multicolumn{1}{l|}{ Cl M } & Cl AM & F M & F AM & OH M & OH AM \\
\hline $\mathrm{E}_{\mathrm{a}}$ & 34.7 & 41.3 & 39.9 & 46.4 & 42.2 & 48.9 & 51.1 & 56.4 \\
\hline$\Delta \mathrm{U}_{\text {prod }}$ & -24.0 & -21.3 & -24.8 & -21.8 & -9.92 & -19.5 & -22.1 & -18.0 \\
\hline
\end{tabular}

Table 7. Calculated difference energies $(\mathrm{kcal} / \mathrm{mol})$ of the transition state and product for Markovnikov and anti-Markovnikov pathways using MP2.

\begin{tabular}{|r|r|r|r|r|r|r|r|r|}
\hline Species & Br M & Br AM & \multicolumn{1}{l|}{ Cl M } & Cl AM & F M & F AM & OH M & OH AM \\
\hline $\mathrm{E}_{\mathrm{a}}$ & 40.3 & 45.8 & 44.4 & 50.1 & 47.4 & 53.9 & 55.9 & 60.9 \\
\hline$\Delta \mathrm{U}_{\text {prod }}$ & -23.8 & -21.3 & -24.9 & -22.0 & -13.7 & -19.0 & -21.9 & -18.0 \\
\hline
\end{tabular}


Table 8. Calculated difference energies of the transition state and product for Markovnikov and anti- Markovnikov pathways based on the COSMO correction for the reaction field due to solvation.

\begin{tabular}{|r|r|r|r|r|r|r|r|r|}
\hline Species & Br M & Br AM & \multicolumn{1}{l|}{ Cl M } & Cl AM & F M & F AM & OH M & OH AM \\
\hline $\mathrm{E}_{\mathrm{a}}$ & -16.3 & -11.6 & -12.7 & -10.3 & -4.1 & -3.2 & 0.7 & 1.4 \\
\hline$\Delta \mathrm{U}_{\text {prod }}$ & -1.0 & -0.7 & -0.2 & 0.0 & -5.3 & 1.8 & 1.8 & 1.8 \\
\hline
\end{tabular}

Table 9. Hirshfeld charge distributions for the M and AM transition states, respectively, for the reaction of HX with 1-propene.

\begin{tabular}{|c|c|c|c|c|c|c|c|c|}
\hline Atom & $\mathrm{O}-\mathrm{M}$ & $\mathrm{O}-\mathrm{AM}$ & $\mathrm{F}-\mathrm{M}$ & $\mathrm{F}-\mathrm{AM}$ & $\mathrm{Cl}-\mathrm{M}$ & $\mathrm{Cl}-\mathrm{AM}$ & $\mathrm{Br}-\mathrm{M}$ & $\mathrm{Br}-\mathrm{AM}$ \\
\hline $\mathrm{C} 3$ & -0.0908 & -0.1047 & -0.0825 & -0.0941 & -0.0937 & -0.0876 & -0.0887 & -0.0869 \\
\hline $\mathrm{H}$ & 0.0469 & 0.0312 & 0.0552 & 0.0372 & 0.0576 & 0.0436 & 0.0469 & 0.0443 \\
\hline $\mathrm{H}$ & 0.0527 & 0.0289 & 0.0576 & 0.0423 & 0.0633 & 0.0486 & 0.0588 & 0.0493 \\
\hline $\mathrm{H}$ & 0.0465 & 0.0347 & 0.0768 & 0.0436 & 0.0668 & 0.0489 & 0.0656 & 0.0486 \\
\hline $\mathrm{C} 2$ & 0.0736 & -0.0973 & 0.1011 & -0.0628 & 0.1087 & -0.0412 & 0.1047 & -0.039 \\
\hline $\mathrm{H}$ & 0.0559 & 0.0712 & 0.0666 & 0.0472 & 0.0712 & 0.0594 & 0.0696 & 0.061 \\
\hline $\mathrm{C} 1$ & -0.1597 & 0.1267 & -0.1218 & 0.0569 & -0.0773 & 0.0588 & -0.0768 & 0.0558 \\
\hline $\mathrm{H}$ & 0.0283 & 0.0321 & 0.0453 & 0.0839 & 0.0614 & 0.0732 & 0.0613 & 0.0715 \\
\hline $\mathrm{H}$ & 0.0334 & 0.0586 & 0.0491 & 0.0708 & 0.0642 & 0.0757 & 0.0686 & 0.0736 \\
\hline $\mathrm{X}$ & -0.2749 & -0.2611 & -0.3046 & -0.294 & -0.3782 & -0.3475 & -0.3747 & -0.3361 \\
\hline $\mathrm{H}$ & 0.0654 & 0.0275 & 0.0577 & 0.0687 & 0.0559 & 0.068 & 0.0649 & 0.0583 \\
\hline $\mathrm{H}$ & 0.1222 & 0.0531 & $\mathrm{NA}$ & $\mathrm{NA}$ & $\mathrm{NA}$ & $\mathrm{NA}$ & $\mathrm{NA}$ & $\mathrm{NA}$ \\
\hline
\end{tabular}


Table 10. Fukui function and softness parameter difference functions for the transition state (TS) relative to the ground state of the four Markovnikov addition reactions studied

\begin{tabular}{|c|c|c|c|c|c|c|}
\hline $\mathrm{AM} \mathrm{Br}$ & Site & $\Delta s_{i}$ & $f_{i}^{\ddagger} \Delta S$ & $S^{0} \Delta f_{i}$ & $\Delta f_{i}$ & $\Delta S$ \\
\hline \multirow[t]{2}{*}{$\mathrm{TS}$} & $\mathrm{C} 1$ & 3.7199 & 5.2364 & -1.5165 & -0.1565 & 24.7 \\
\hline & $\mathrm{C} 2$ & 0.3126 & 1.7661 & -1.4535 & -0.1500 & 24.7 \\
\hline $\mathrm{M} \mathrm{Br}$ & Site & $\Delta s_{i}$ & $f_{i}^{\ddagger} \Delta S$ & $S^{0} \Delta f_{i}$ & $\Delta f_{i}$ & $\Delta S$ \\
\hline \multirow[t]{2}{*}{$\mathrm{TS}$} & $\mathrm{C} 1$ & -0.4593 & 1.5950 & -2.0543 & -0.2120 & 34.3 \\
\hline & $\mathrm{C} 2$ & 5.8379 & 6.2255 & -0.3876 & -0.0400 & 34.3 \\
\hline $\mathrm{AM} \mathrm{Cl}$ & Site & $\Delta s_{i}$ & $f_{i}^{\ddagger} \Delta S$ & $S^{0} \Delta f_{i}$ & $\overline{\Delta f_{i}}$ & $\Delta S$ \\
\hline \multirow[t]{2}{*}{$\mathrm{TS}$} & $\mathrm{C} 1$ & 3.1270 & 3.4420 & -0.3159 & -0.0325 & 15.23 \\
\hline & $\mathrm{C} 2$ & -0.1403 & 1.2260 & -1.3663 & -0.1410 & 15.23 \\
\hline $\mathrm{M} \mathrm{Cl}$ & site & $\Delta s_{i}$ & $f_{i}^{\ddagger} \Delta S$ & $S^{0} \Delta f_{i}$ & $\Delta f_{i}$ & $\Delta S$ \\
\hline \multirow[t]{2}{*}{ TS } & $\mathrm{C} 1$ & -1.1064 & 0.9237 & -2.0301 & -0.2095 & 18.35 \\
\hline & $\mathrm{C} 2$ & 3.4617 & 3.7040 & -0.2423 & -0.0250 & 18.35 \\
\hline AM F & site & $\Delta s_{i}$ & $f_{i}^{\ddagger} \Delta S$ & $S^{0} \Delta f_{i}$ & $\Delta f_{i}$ & $\Delta S$ \\
\hline \multirow[t]{2}{*}{ TS } & $\mathrm{C} 1$ & 1.2174 & 1.2852 & -0.0678 & -0.0070 & 5.11 \\
\hline & $\mathrm{C} 2$ & -0.7182 & 0.4931 & -1.2113 & -0.1250 & 5.11 \\
\hline M F & site & $\Delta s_{i}$ & $f_{i}^{\ddagger} \Delta S$ & $S^{0} \Delta f_{i}$ & $\Delta f_{i}$ & $\Delta S$ \\
\hline \multirow[t]{2}{*}{ TS } & $\mathrm{C} 1$ & -0.9405 & 0.5275 & -1.4680 & -0.1515 & 4.93 \\
\hline & $\mathrm{C} 2$ & 1.0627 & 1.0821 & -0.0194 & -0.0020 & 4.93 \\
\hline $\mathrm{AM} \mathrm{OH}$ & site & $\Delta s_{i}$ & $f_{i}^{\ddagger} \Delta S$ & $S^{0} \Delta f_{i}$ & $\Delta f_{i}$ & $\Delta S$ \\
\hline \multirow[t]{2}{*}{ TS } & $\mathrm{C} 1$ & -1.9351 & 0.2258 & -2.1609 & -0.2230 & 6.36 \\
\hline & $\mathrm{C} 2$ & -0.8061 & 0.5311 & -1.3372 & -0.1380 & 6.36 \\
\hline $\mathrm{M} \mathrm{OH}$ & site & $\Delta s_{i}$ & $f_{i}^{\ddagger} \Delta S$ & $S^{0} \Delta f_{i}$ & $\Delta f_{i}$ & $\Delta S$ \\
\hline \multirow[t]{2}{*}{$\mathrm{TS}$} & $\mathrm{C} 1$ & -1.7221 & 0.2934 & -2.0155 & -0.2080 & 5.81 \\
\hline & $\mathrm{C} 2$ & 0.9382 & 1.1562 & -0.2180 & -0.0225 & 5.81 \\
\hline
\end{tabular}




\section{Figures}

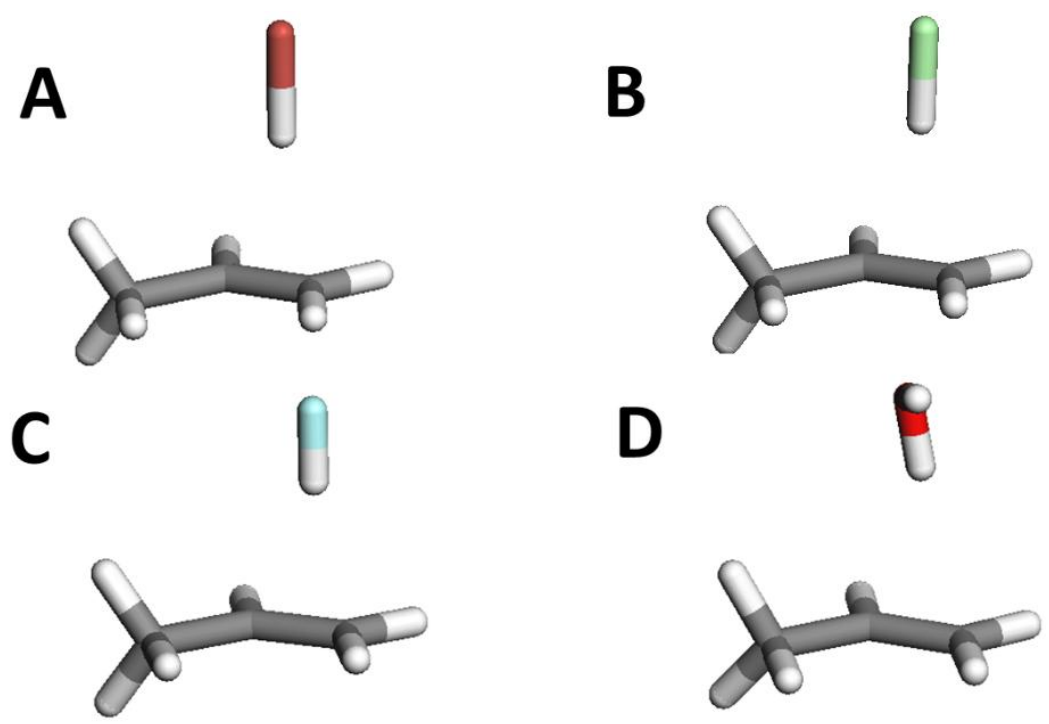

Figure 1. Geometry optimized structures for the HX series of molecules with propene, showing the tendency of the $\mathrm{H}$ atom to be directed towards the $\pi$-bond. The molecules adding to propene are A.) $\mathrm{HBr}$ B.) $\mathrm{HCl} \mathrm{C.)} \mathrm{HF}$, D.) $\mathrm{H}_{2} \mathrm{O}$. 

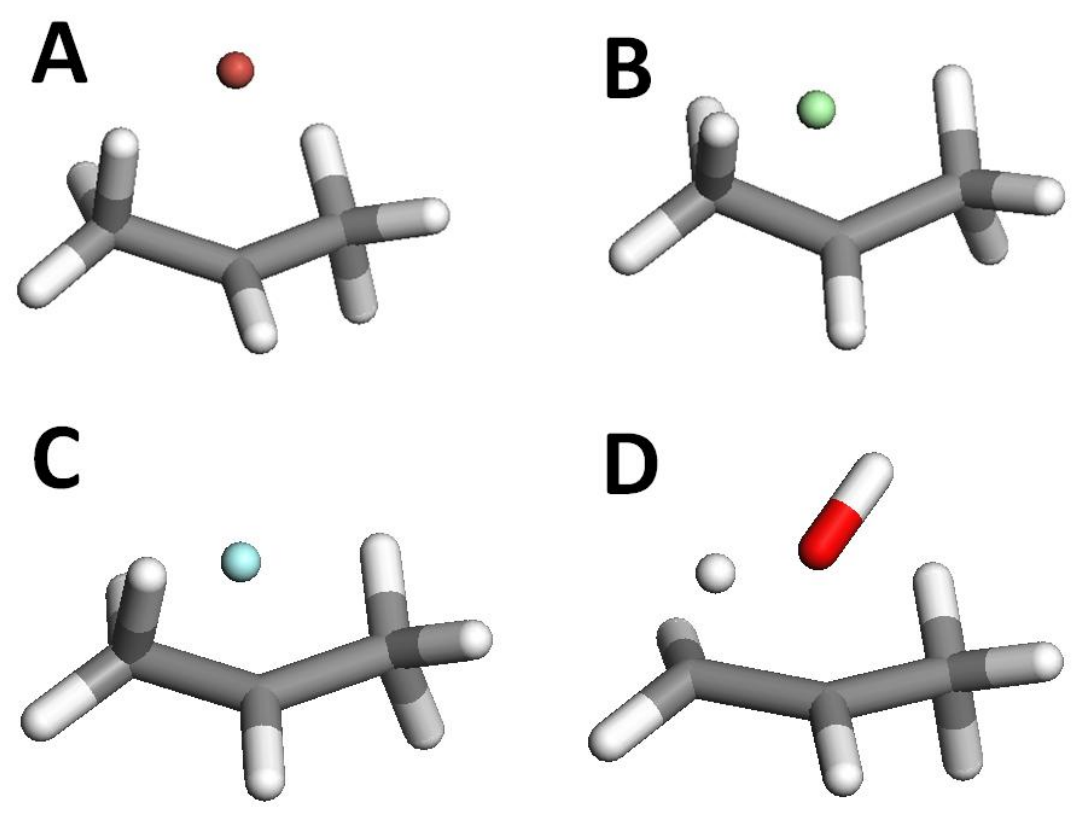

Figure 2. Markovnikov transition states calculated using NEB and DIMER and validated using IRC. The molecules adding to propene are A.) $\mathrm{HBr}$ B.) $\mathrm{HCl} \mathrm{C.)} \mathrm{HF}$, D.) $\mathrm{H}_{2} \mathrm{O}$. 
$A^{\circ}$

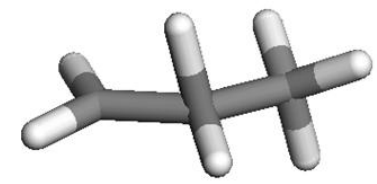

C

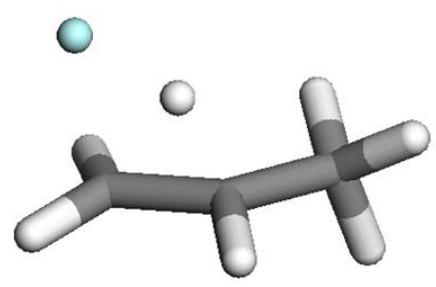

B $^{\circ}$

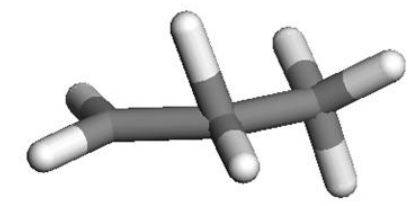

D

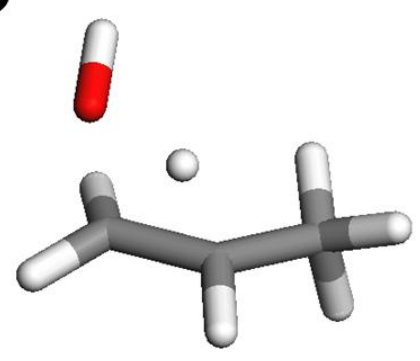

Figure 3. Anti-Markovnikov pathway transition states calculated using NEB and DIMER and validated using IRC. The molecules adding to propene are A.) $\mathrm{HBr}$ B.) $\mathrm{HCl} \mathrm{C}$.) $\mathrm{HF}$, D.) $\mathrm{H}_{2} \mathrm{O}$. 


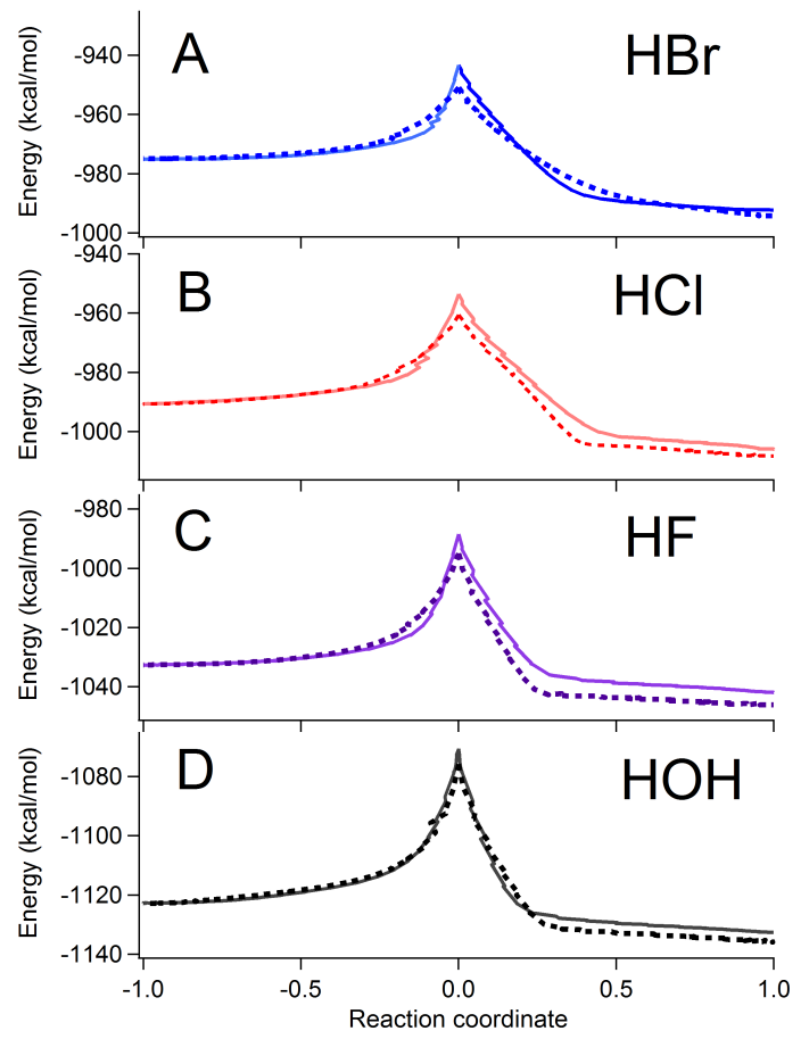

Figure 4. IRC calculations based on the transition state obtained from NEB and DIMER. The panels A-D are plotted on the same scale so that the trend in the barrier heights can be observed. The anti-Markovnikov and Markovnikov trajectories are shown in solid and dotted lines, respectively. 


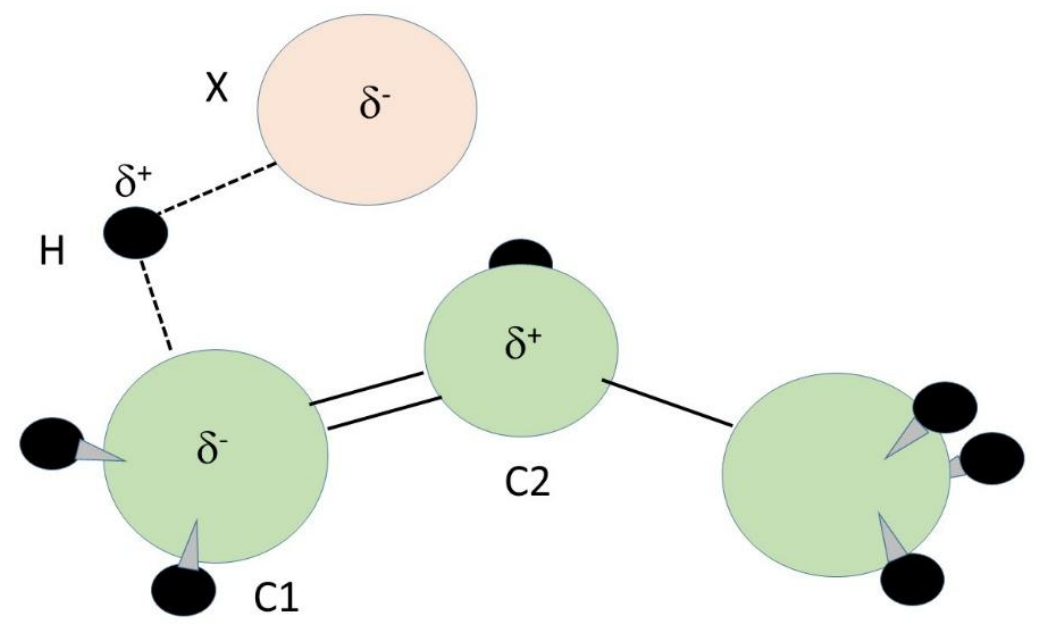

Figure 5. Depiction of the charge distribution in the transition state of the Markovnikov pathway. There is a dipole across the $\mathrm{C} 1-\mathrm{C} 2$ bond, but also involving each of the adding species $\mathrm{H}$ and $\mathrm{X}$. Because of the two dipoles involved one can characterize transition state as a quadrupole. 


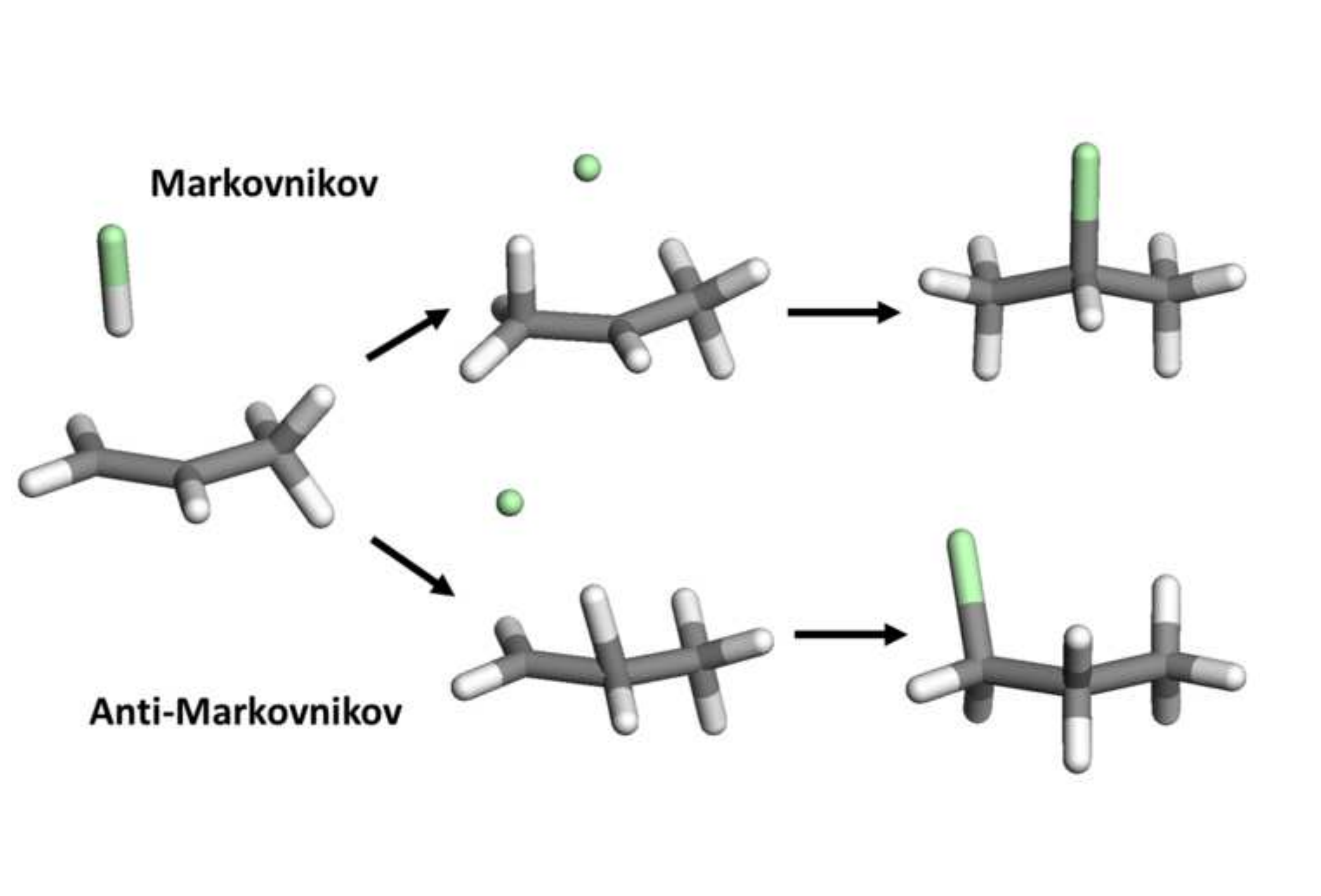

Anti-Markovnikov

-

\begin{abstract}
.
\end{abstract}

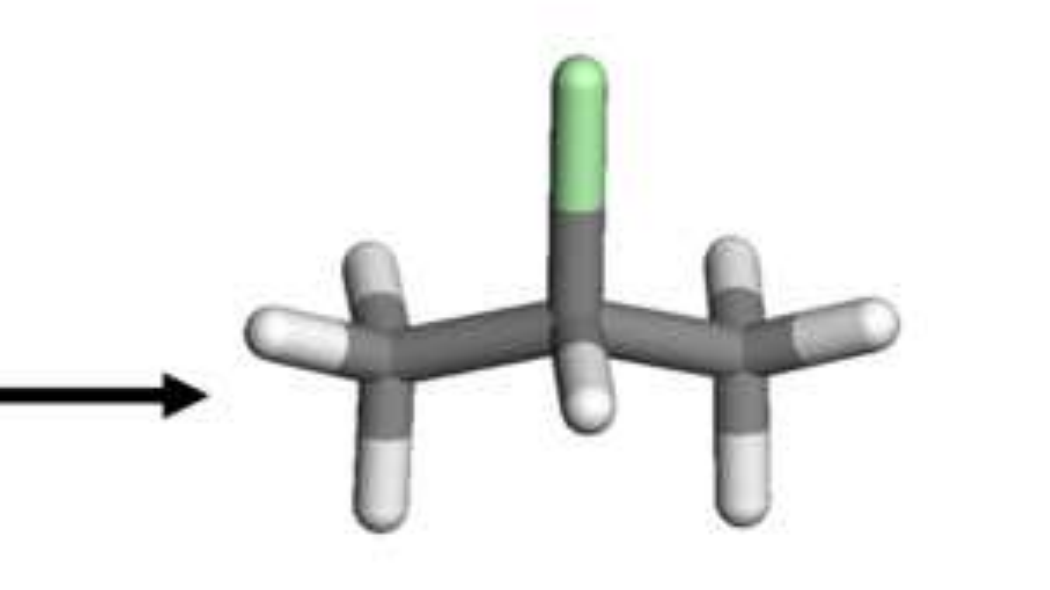

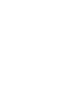

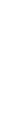

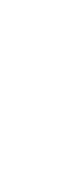

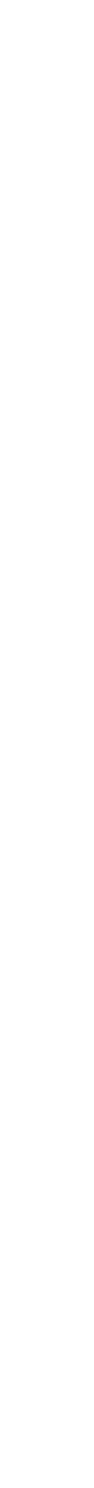

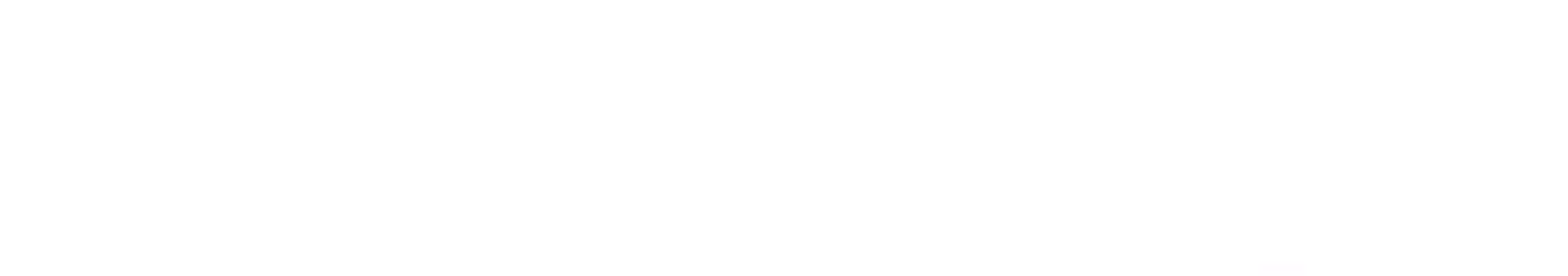
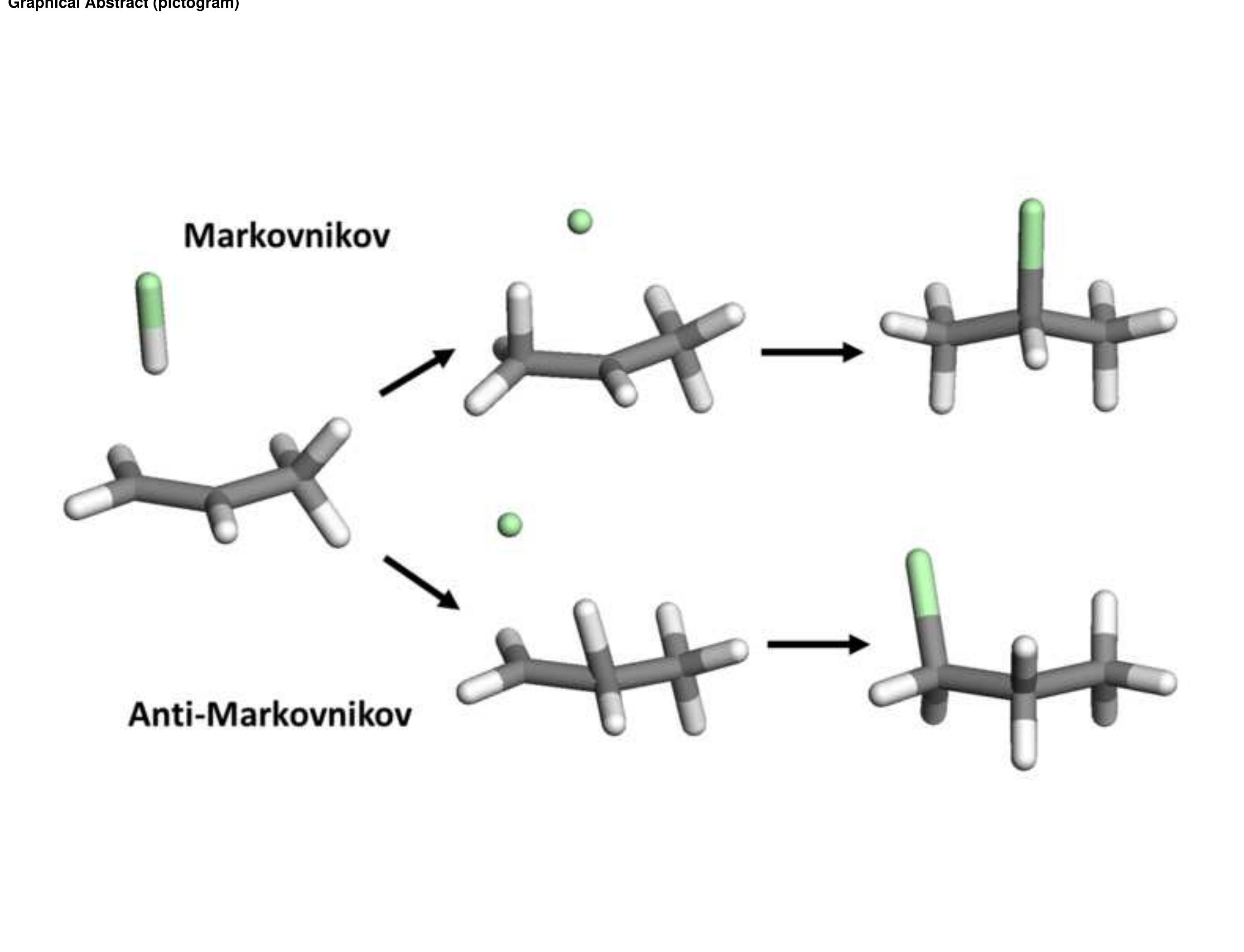

.

.

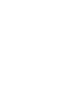
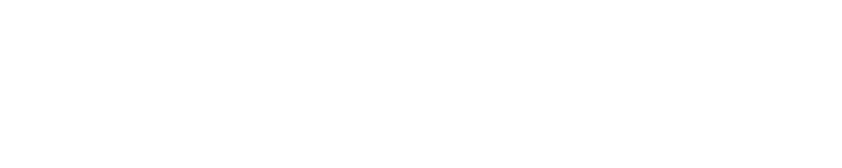